\title{
Моделирование пространственного распределения чужеродных видов растений с использованием данных дистанционного зондирования на примере Paulownia tomentosa
}

\author{
А. В. Егошин $\bowtie$ \\ Сочинский национальный парк, Российская Федерачия (354002, г. Сочи, Курортный пр., 74) \\ Поступила в редакиию 4.09.2019 \\ Принята к публикаиии 26.02.2020
}

\begin{abstract}
Аннотация: Цель: Провести сравнительный анализ использования данных дистанционного зондирования, а также биоклиматических и эколого-географических данных для моделирования пространственного распределения чужеродных видов на примере Paulownia tomentosa.

Meтоды: Моделирование проведено среде SAHM методом максимальной энтропии. При этом в качестве источника предикторных переменных использовали биоклиматические растры Worldclim, экспозиции, высоты над уровнем моря, уклона, застроенности территории, чистой первичной продуктивности, топографического индекса влажности, удалённости точек пространства от населённых пунктов, дорог и водотоков, полученные в среде ArcGIS, а также семиканальные спутниковые снимки Landsat 5.

Результаты: Установлено, что самыми эффективными предикторами пространственного распределения павловнии являются высота над уровнем моря, топографический индекс влажности, пространственное расположение речной сети, годовая сумма осадков, максимальная температура самого теплого месяца года, средняя температура самой сухой четверти года, сумма осадков во влажной четверти года, а также спутниковый снимок Landsat 5 , сделанный в мае.

Bыводы: Комплекс использованных пространственных данных позволил выявить места, наиболее пригодные для произрастания паволовнии войлочной, которые преимущественно располагаются в долинах горных рек на высотных отметках от 20 до 240 метров над уровнем моря. Суммарная площадь территории Большого Сочи, наиболее пригодная для произрастания павловнии составляет 208 кв. км $(5,9 \%)$. В будущем климатические изменения (сценарии: RCP2.6, RCP4.5, RCP6.0) будут способствовать дальнейшему распространению Paulownia tomentosa. Самый экстремальный сценарий климатических изменений (RCP8.5) будет сопровождаться подавлением роста и развития Paulownia tomentosa.
\end{abstract}

Ключевые слова: чужеродные виды, инвазии, Paulownia tomentosa, дистанционное зондирование.

\section{Modeling of Spatial Distribution of Alien Species of Plants Using Remote Sensing Data on the Example of Paulownia tomentosa}

\section{A. V. Egoshin $\bowtie$}

Abstract: Purpose: The purpose of the work is to conduct a comparative analysis of the use of remote sensing data, as well as bioclimatic and ecological-geographical data for modeling the spatial distribution of alien species, using the example of the Paulownia tomentosa species.

Methods: The modeling was performed by the SAHM software using the maximum entropy method. During analysis, we used Worldclim bioclimatic rasters, exposure, elevation, slope, built-up area, net primary productivity, topographic humidity index, the remoteness of spatial points from settlements, roads, and rivers, as well as Landsat 5 satellite images.

Results: We found that the most effective predictors of the spatial distribution of paulownia are altitude,

() Егошин А. В., 2020

E-mail: ecoid@ya.ru

cc) (i) Контент доступен под лицензией Creative Commons Attribution 4.0 License.

The content is available under Creative Commons Attribution 4.0 License. 
topographic humidity index, spatial location of the river network, annual precipitation, maximum temperature of the warmest month of the year, average temperature of the driest quarter of the year, precipitation in the wet quarter of the year as well as a Landsat 5 satellite image taken in May.

Conclusions: The complex of spatial data used made it possible to identify the places most suitable for growing paulownia, which is mainly located in mountain river valleys at altitudes from 20 to 240 meters above sea level. The total area of the territory of Greater Sochi, the most suitable for the growth of paulownia is 208 sq. Km. (5.9\%). Climate change (scenarios: RCP2.6, RCP4.5, RCP6.0) will contribute to the further spread of Paulownia tomentosa. The most extreme climate change scenario (RCP8.5) will reduce the spread of Paulownia tomentosa.

Key words: alien species, invasion, Paulownia tomentosa, remote sensing.

\section{ВВЕДЕНИЕ}

Привнесение элементов чужеродной флоры влечет за собой изменение множества параметров экосистем (биоразнообразие, обилие видов, биологическая продуктивность, интенсивность круговорота веществ и т.д.). Такие изменения могут оказаться фатальными для некоторых аборигенных видов. В глобальном масштабе это приводит к унификации флоры и представляет серьезную угрозу для биоразнообразия планеты [2, 10, 13]. В результате интенсификации процессов глобализации и климатических изменений эта угроза с каждым годом лишь увеличивается.

Успешность произрастания чужеродных видов на новой родине вызвана комплексом факторов.

Во-первых, многие пришлые виды обладают четко-выраженными физиологическими конкурентными преимуществами [8]. Эти преимущества заключаются в высокой скорости роста и созревания плодов, эффективных способах распространения семян, которые к тому же обладают высокой энергией роста. Именно поэтому, многие иноземные виды являются у себя на родине видами начальных стадий сукцессий [18]. Кроме того, некоторые успешные чужеродные виды вступают в различного рода аллелопатические взаимодействия, подавляя рост и развитие конкурентов. Как результат, в отсутствие специализированных фитофагов иноземные виды могут получать существенные конкурентные преимущества на новой родине. Значительную роль в успешной натурализации чужеродных видов играет видовое разнообразие экосистемы-акцептора $[1,3,8,11,14]$. Экосистемы, отличающиеся высоким видовым разнообразием, как правило, более устойчивы к внедрению иноземных видов.

Существенную роль в проникновении иноземных видов играют и биоклиматические условия новой родины [7]. Более комфортные климатические условия территории, позволяют экосистемам «принимать» большее число разнообразных чужеродных видов.
Значительное влияние на процессы распространения адвентивных видов оказывает антропогенная деятельность, которая сопровождается различного рода нарушениями экосистем [4, 6, 12, 15, 17]. Эти нарушения влекут за собой изменение видового состава и обилия видов, в результате чего в экосистемах появляются свободные ресурсы, на которые и «претендуют» чужеродные виды.

Таким образом, процесс биологических инвазий имеет иерархическую структуру. Климат - доминирующий фактор на макроуровне, тогда как топографические особенности местности и характер землепользования играют важную роль на мезоуровне, и, наконец, в локальных масштабах почвенные условия, нарушения растительного покрова и биотические взаимодействия играют детерминирующую роль в распространении пришлых видов.

Последние достижения вычислительных технологий вкупе с доступностью большого количества различных данных о состоянии окружающей среды, в том числе и данных дистанционного зондирования, позволяют оценить всю вышеупомянутую многомерную иерархическую структуру факторов и перейти от узколокальных полевых исследований пространственного распределения видов к более широкомасштабным, а также сделать прогноз, как климатические изменения повлияют на распространение адвентивных видов в будущем.

\section{МЕТОДИКА}

При моделировании пространственного распределения чужеродных видов на примере Paulownia tomentosa (Thunb.) Steud. в качестве источника предикторных переменных использовали биоклиматические растры Worldclim (таблица 1), а также семиканальные спутниковые снимки Landsat 5 с разрешением 30 метров, представленные в свободном доступе на сайте геологической службы США (www.earthexplorer.usgs.gov) (таблица 2). Для того, чтобы учесть фенологические особенности Paulownia tomentosa (Thunb.) Steud и других растений экосистем, подвергшихся инва- 
Моделирование пространственного распределения чужеродных видов растений с использованием данных дистанщионного зондирования на примере Paulownia tomentosa

Таблица 1

Биоклиматические переменные BIOCLIM

[Table 1. Bioclimatic variables BIOCLIM]

\begin{tabular}{|c|c|}
\hline $\begin{array}{c}\text { Код } \\
\text { [Code] }\end{array}$ & $\begin{array}{c}\text { Биоклиматический параметр } \\
\text { [Bioclimatic variable] }\end{array}$ \\
\hline $\mathrm{BIO} 1$ & Средняя годовая температура \\
\hline $\mathrm{BIO} 2$ & Средняя суточная амплитуда температуры \\
\hline $\mathrm{BIO} 3$ & Изотермичность (BIO1/BIO7) * 100 \\
\hline $\mathrm{BIO} 4$ & Стандартное отклонение температур \\
\hline BIO5 & Максимальная температура самого теплого месяца года \\
\hline BIO6 & Минимальная температура самого холодного месяца года \\
\hline $\mathrm{BIO} 7$ & Годовая амплитуда температуры (BIO5-BIO6) \\
\hline $\mathrm{BIO} 8$ & Средняя температура самой влажной четверти года \\
\hline BIO9 & Средняя температура самой сухой четверти года \\
\hline $\mathrm{BIO10}$ & Средняя температура самой теплой четверти года \\
\hline BIO11 & Средняя температура самой холодной четверти года \\
\hline BIO12 & Годовая сумма осадков \\
\hline BIO13 & Сумма осадков в самом влажном месяце года \\
\hline $\mathrm{BIO14}$ & Сумма осадков в самом сухом месяце года \\
\hline $\mathrm{BIO15}$ & Коэффициент вариации осадков \\
\hline BIO16 & Сумма осадков во влажной четверти года \\
\hline BIO17 & Сумма осадков в сухой четверти года \\
\hline BIO18 & Сумма осадков в самой теплой четверти года \\
\hline BIO19 & Сумма осадков в самой холодной четверти года \\
\hline
\end{tabular}

Таблица 2

Спектральные каналы спутниковых снимков, полученных с помощью сенсора Thematic Mapper (TM) Landsat 5

[Table 2. Spectral bands of satellite imagery obtained Thematic Mapper (TM) Landsat 5 sensor]

\begin{tabular}{|l|c|}
\hline \multicolumn{1}{|c|}{$\begin{array}{c}\text { Спектральные каналы } \\
\text { [Spectral band] }\end{array}$} & $\begin{array}{c}\text { Длина волны, микрометры } \\
\text { [Wavelength }(\mu \mathrm{m})]\end{array}$ \\
\hline $1-$ Голубой & $0,45-0,52$ \\
\hline $2-$ Зеленый & $0,52-0,60$ \\
\hline $3-$ Красный & $0,63-0,69$ \\
\hline $4-$ Ближний инфракрасный & $0,76-0,90$ \\
\hline $5-$ Коротковолновый инфракрасный 1 & $1,55-1,75$ \\
\hline 6- Тепловой инфракрасный & $10,40-12,50$ \\
\hline $7-$ Коротковолновый инфракрасный 2 & $2,08-2,35$ \\
\hline
\end{tabular}

зии, были использованы ежемесячные снимки Landsat, сделанные с апреля по октябрь.

Вышеупомянутые спектральные каналы снимков Landsat использовали для получения индексов NDVI (нормализованный относительный индекс растительности) и SAVI (индекс растительности с поправкой на отражение от почвенного слоя). NDVI и SAVI являются одними из наиболее часто используемыми спектральными индексами для оценки растительной биомассы, видового состава и состояния растительного покрова.

Помимо этого, производили трансформацию каналов (Tasseled-Cap Transformation) с получени- ем нового набора каналов: В - «яркость», $\mathrm{G}$ - «зеленость» и $\mathrm{W}-$ «влажность»).

Кроме того, при анализе использовали другие растровые данные, полученные в среде ArcGIS: экспозиция, высота над уровнем моря (м), уклон (градусы), застроенность территории (\%/км²), npp - чистая первичная продуктивность (кг-С/м²/год), топографический индекс влажности, удаленность точек пространства от населенных пунктов, дорог и водотоков.

При моделировании пространственного распределения было использовано 100 точек мест произрастания Paulownia tomentosa, и аналогич- 


\section{A. B. Егошин}

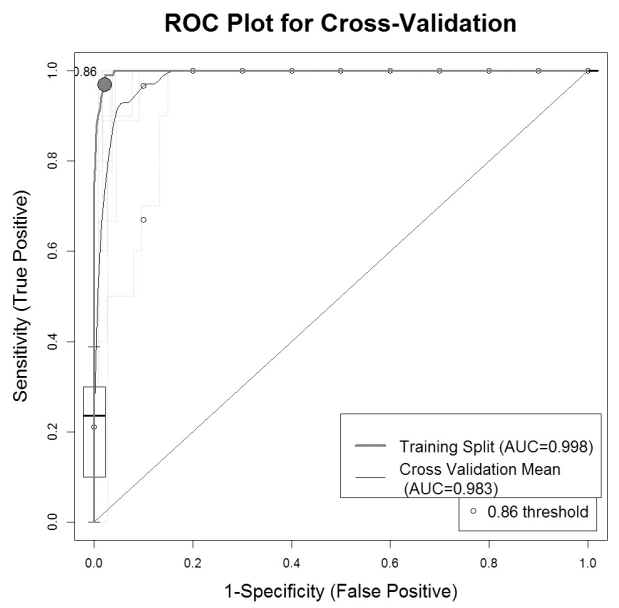

a

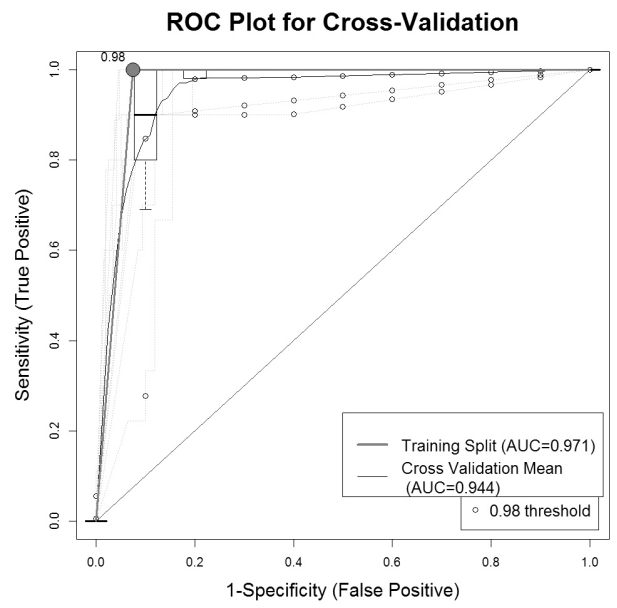

c

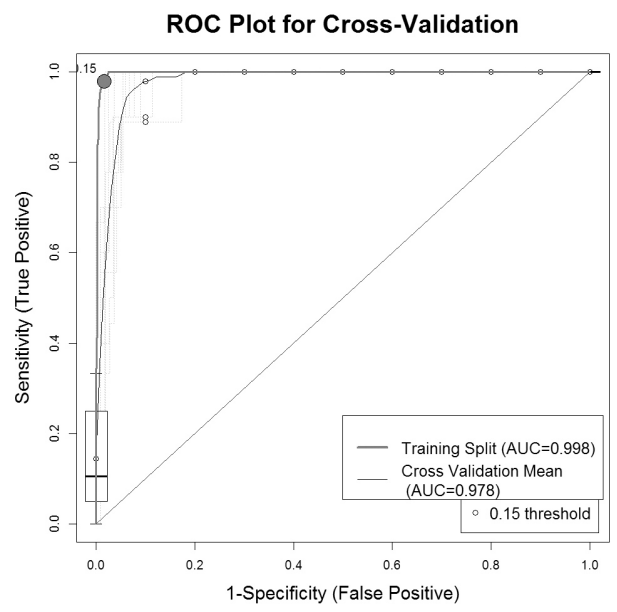

e

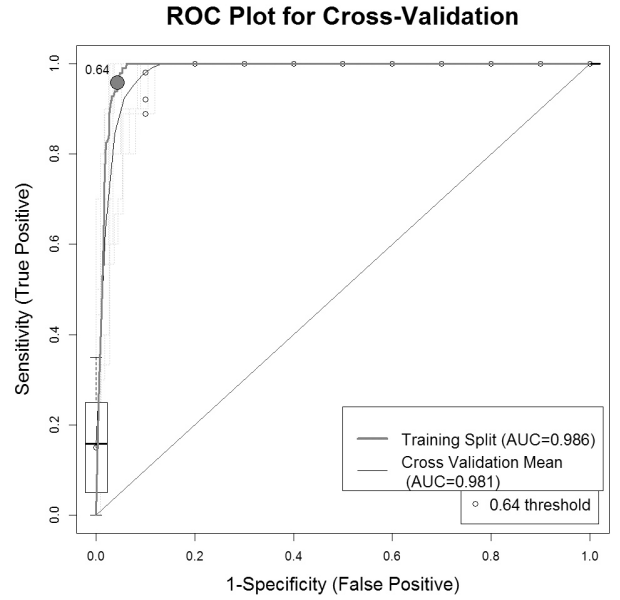

b

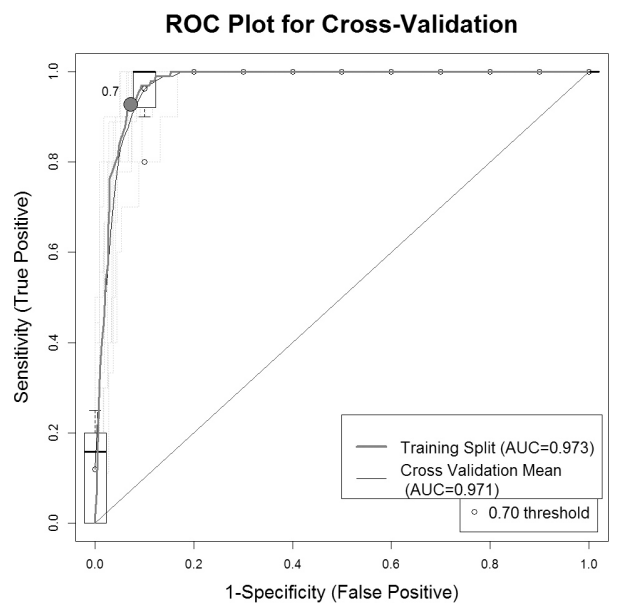

d

Puc. 1. ROC-кривые, полученные в результате моделирования с использованием различных методов регрессионного анализа: a - BRT, b - GLM, c - MARS, d - RF, e - maxent. Величины площадей, ограниченных ROC-кривыми осями значений с нулевой степенью прогнозирования (диагональные линии) во всех случаях превышают 0.7

[Fig. 1. The curves obtained during modeling using various methods of regression analysis: a - BRT, b-GLM, $\mathrm{c}-$ MARS, $\mathrm{d}-\mathrm{RF}$, e - maxent. The values of the areas bounded by the ROC curves exceed 0.7] 
Моделирование пространственного распределения чужеродных видов растений с использованием данных дистанционного зондирования на примере Paulownia tomentosa

Таблица 3

Оценка эффективности использованных методов моделирования пространственного распределения Paulownia tomentosa

[Table 3. Evaluation of the efficiency of the methods used to model the spatial distribution of the species Paulownia tomentosa]

\begin{tabular}{|l|c|c|c|c|c|}
\hline \multirow{2}{*}{ Methods } & AUC* & PCC** & Sensitivity & Specificity & TSS*** \\
\hline BRT & 0.998 & 98 & 0.97 & 0.98 & 0.95 \\
\hline RF & 0.971 & 94 & 0.72 & 0.96 & 0.69 \\
\hline MARS & 0.944 & 90 & 0.88 & 0.90 & 0.79 \\
\hline GLM & 0.981 & 95 & 0.92 & 0.95 & 0.87 \\
\hline Maxent & 0.978 & 95 & 0.72 & 0.97 & 0.69 \\
\hline
\end{tabular}

Примечание: *AUC - Area Under Curve, **PCC - Percent Correctly Classified), ***TSS = Sensitivity+Specificity -1

ное количество точек мест, где павловния не встречается.

Моделирование проводили с использованием различных методов регрессионного анализа: Boosted Regression Trees (BRT), Random Forest (RF), Multivariate Adaptive Regression Splines (MARS), Generalized Linear Model (GLM) и Maxent в среде Assisted Habitat Modeling (SAHM).

Оценка качества моделей была проведена в среде SAHM с построением ROC-кривых (Receiver Operating Characteristic) и их AUC (Area Under Curve). Значение AUC равное 0,5 свидетельствует о том, что прогноз пространственного распределения вида, полученный в результате моделирования, носит случайный характер. Значения AUC от 0,5 до 0,7 указывают на слабую связь, в то время как значения AUC от 0,7 до 1,0 свидетельствуют о существенной точности моделирования пространственного распределения вида. Кроме того, производили расчетРСС (Percent Correctly Classified), оценивающего чувствительность (Sensitivity) и специфичность (Specificity) на основе пороговых значений. При этом под чувствительностью понимается доля корректно классифицированных присутствий особей вида, а под специфичностью доля корректно классифицированных отсутствий особей вида. Показатель TSS (True Skill Statistic) рассчитывался следующим образом: TSS $=$ Sensitivity + Specificity -1 .

Оценку влияния климатических изменений на пространственное распределение павловнии войлочной в будущем (2050 и 2070 годы) проводили в среде Maxent, используя растровые слои BIOCLIM, рассчитанные с использованием климатической модели CCSM4 для четырех репрезентативных траекторий концентраций (RCP), разработанных Межправительственной группой по изменению климата (IPCC). RCP являются сценариями климатических состояний, характеризующими величину антропогенно обусловленного радиационного воздействия, достигаемого к 2100 году по сравнению с 1750 годом $(2,6 ; 4,5 ; 6,0$ и 8,5 Вт/м²). Согласно этим сценариям вероятные оценки увеличения глобальной температуры к концу 2100 года составят: $0,2-1,8^{\circ} \mathrm{C}(\mathrm{RCP} 2.6) ; 1,0-2,6^{\circ} \mathrm{C}$ (RCP4.5); $1,3-3,2^{\circ} \mathrm{C}(\mathrm{RCP} 6.0) ; 2,6-4,8^{\circ} \mathrm{C}(\mathrm{RCP} 8.5)$.

\section{РЕЗУЛЬТАТЫ}

Общее число преднамеренно и непреднамеренно интродуцированных видов на юге Российского Причерноморья превышает 2000. Большинство произрастает на улицах населенных пунктов, приусадебных участках, в парках и ботанических садах, не внедряясь в естественные экосистемы. Общее количество наиболее агрессивных чужеродных видов, способных внедряться в экосистемы различной степени нарушенности составляет 182 [5]. Одним из таких видов является Павловния войлочная, которая способна вторгаться в естественно-нарушенные экосистемы (вывалы деревьев, берега горных рек, нарушаемые во время паводков). Зачастую под пологом павловнии появляются другие виды чужеродных травянистых растений.

Графики ROC кривых, полученные в результате использования пяти методов анализа: Boosted Regression Trees (BRT), Random Forest (RF), Multivariate Adaptive Regression Splines (MARS), Generalized Linear Model (GLM) и Maxent в среде Assisted Habitat Modeling (SAHM) представлены на рисунке 1 . 


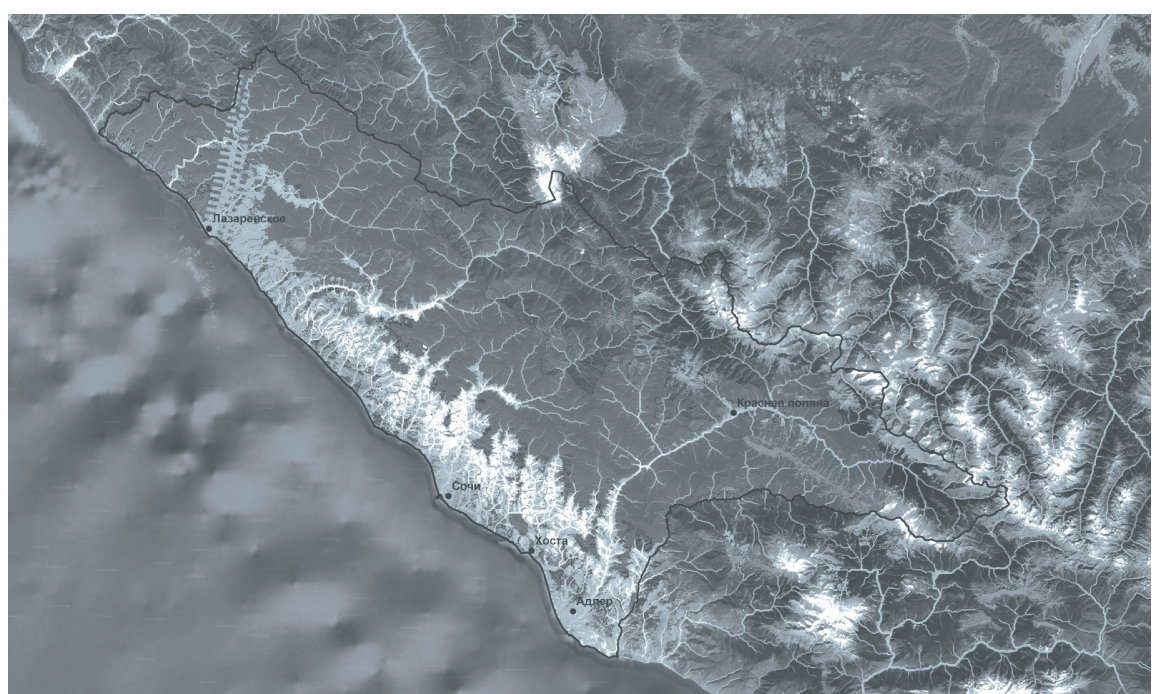

Puc. 2. Результат суммирования бинарных карт. Черная линия - граница Большого Сочи; цвета: от серого к белому в прибрежной части исследуемого региона указывают на количество методов моделирования (BRT, RF, MARS, GLM и Maxent), свидетельствующих о пригодности территории для произрастания павловнии. Белым цветом обозначены участки пригодные для произрастания павловнии согласно всем, пяти использованным методам моделирования

[Fig. 2. The result of the summation of binary maps. The black line is the border of Greater Sochi; colors: from gray to white in the coastal part of the study region indicate the number of modeling methods (BRT, RF, MARS, GLM and Maxent), indicating the suitability of the area for the growth of paulownia. White color indicates areas suitable for paulownia growth according to all five used modeling methods]

Таблий 4

Эффективность предикторов

[Table 4. Predictors efficiency]

\begin{tabular}{|c|c|c|c|c|}
\hline Предиктор [Predictor] & BRT & $\mathrm{RF}$ & MARS & Maxent \\
\hline ALT & 24.56 & 9.27 & 25.76 & 21.7 \\
\hline BIO12 & 16.87 & 8.85 & 29.81 & 15.6 \\
\hline TIV & 12.66 & 14.13 & 45.72 & 18 \\
\hline BIO5 & 9.71 & 8.57 & 37.19 & 17.2 \\
\hline BIO9 & 7.69 & 8.87 & 100 & 7.9 \\
\hline BIO1 & 5.53 & 8.30 & 28.95 & \\
\hline BIO13 & 5.24 & 8.53 & 27.11 & 0.1 \\
\hline BIO16 & 5.09 & 8.84 & 52.32 & \\
\hline $\mathrm{BIO} 4$ & 4.08 & 7.66 & 23.72 & 3.4 \\
\hline soilph & 2.40 & 7.58 & 31.07 & 0.1 \\
\hline railroads & 2.05 & 5.14 & 24.75 & \\
\hline combined_may_11_Brightness & 1.42 & 4.59 & & \\
\hline BIO10 & & 8.76 & 40.55 & 0.5 \\
\hline BIO6 & & 8.44 & 45.11 & 0.2 \\
\hline BIO11 & & 8.40 & 36.97 & \\
\hline combined_aug_11_B6 & & & 35.08 & \\
\hline combined_aug_11_B4 & & & 34.13 & \\
\hline combined_jul_11_SAVI & & & 32.00 & \\
\hline
\end{tabular}




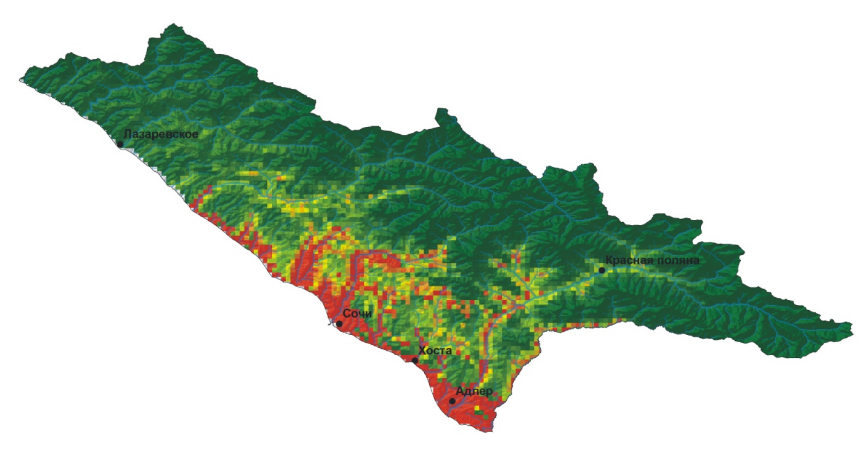

$\mathrm{a}$

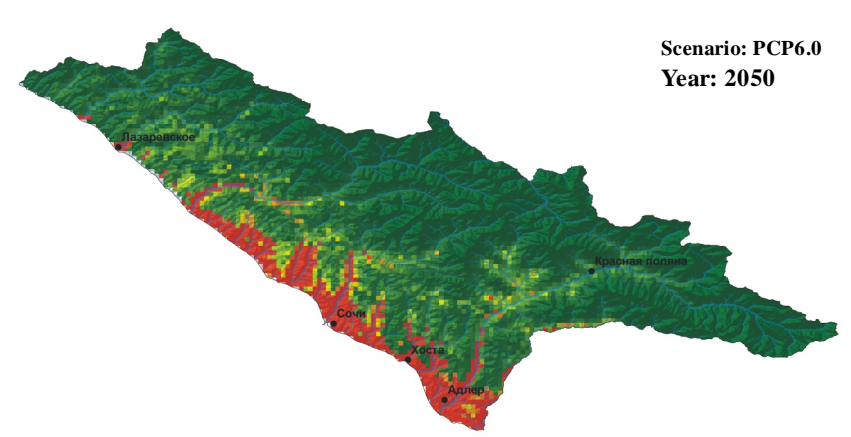

b

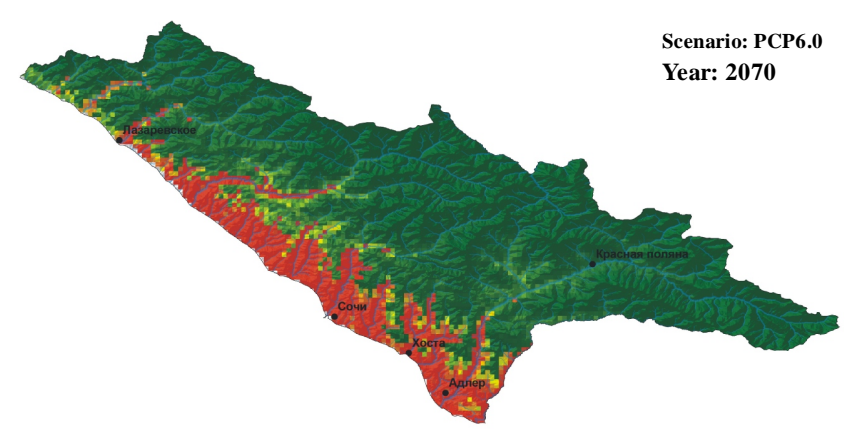

C

Puc. 3. Вероятность соответствия климатических и экологических условий местности биологическим требованиям Павловнии Войлочной: (a) - настоящее время, (b) - 2050 год, (c) - 2070 год (сценарий

RCP6.0). Черным цветом обозначены территории, пригодные для произрастания изучаемого вида

[Fig. 3. The probability of comfort of the climatic and ecological conditions of the area to the biological requirements of Paulownia: (a) - present, (b) - 2050,

(c) - 2070 (scenario RCP6.0). The territories most suitable for the growth of paulownia are marked in black]

Статистическая оценка эффективности использованных методов моделирования пространственного распределения вида Paulownia tomentosa свидетельствует об их высокой эффективности: $\mathrm{AUC}>0.7, \mathrm{PCC}>90.0, \mathrm{TSS}>0.69$ (таблица 3).
Выявление мест, наиболее пригодных для произрастания павловнии провели посредством суммирования растров, полученных в результате использования всех методов анализа.

Результат суммирования бинарныхкарт, полученных в результате применения методов регрессионного анализа: BRT, RF, MARS, GLM и Maxent представлен на рисунке 2.

Согласно рисунку 2 наиболее пригодные места для произрастания павловнии войлочной преимущественно располагаются в долинах рек на высотных отметках от 20 до 240 метров над уровнем моря, хотя отдельные экземпляры вида могут встречаться на высотах 500 метров и более. Суммарная площадь территории Большого Сочи, наиболее пригодная для произрастания павловнии составляет 208 кв. км (5,9\%). Для всех пяти методов моделирования самыми эффективными предикторами из группы географических растров оказались высота над уровнем моря, топографический индекс влажности (TIV) и речная сеть; из биоклиматических растров Bioclim: BIO12 (годовая сумма осадков), ВIO5 (максимальная температура самого теплого месяца года), ВIO9 (средняя температура самой сухой четверти года) и ВIO16 (сумма осадков во влажной четверти года); из спутниковых данных - снимок, сделанный в мае (полученный в результате Tasseled-Cap-трансформации, канал В - «яркость») (таблица 4).

Согласно результатам анализа MARS высокой предиктивной способностью обладают каналы B4 (ближний инфракрасный) и В6 (тепловой инфракрасный).

Результаты прогностического моделирования пространственного распределения Paulownia tomentosa на 2050 и 2070, проведенного в среде MaxEnt, представлены в таблице 5 и на рисунке 3. В результате климатических изменений площадь, пригодная для произрастания Павловнии войлочной будет преимущественно увеличиваться.

Наиболее благоприятные условия для интенсивной экспансии Павловнии в аборигенные экосистемы будут наблюдаться при сценарии климатических изменений RCP6.0. В то время, как самый экстремальный сценарий (RCP8.5) будет сопровождаться подавлением роста и развития Paulownia tomentosa.

\section{ЗАКЛЮЧЕНИЕ}

Согласно комплексу использованных данных и методов моделирования наиболее пригодные места для произрастания павловнии войлочной 
Влияние климатических изменений на распространение Павловнии войлочной на территории Большого Сочи

[Table 5. The impact of climate changes on the spread of Paulownia in Sochi]

\begin{tabular}{|c|c|c|}
\hline \multirow{2}{*}{$\begin{array}{c}\text { Сценарий } \\
\text { [Scenario] }\end{array}$} & $\begin{array}{c}\text { Площадь Большого Сочи, пригодная для } \\
\text { произрастания Paulownia tomentosa, } \mathrm{KM}^{2} \\
\text { [The area of Sochi suitable for growing } \\
\text { Paulownia tomentosa, } \mathrm{km}^{2} \text { ] }\end{array}$ \\
\hline RCP2.6 & 2050 & 2070 \\
\hline RCP4.5 & 120,045 & 281,043 \\
\hline RCP6.0 & 226,119 & 241,374 \\
\hline RCP8.5 & 251,494 & 427,596 \\
\hline
\end{tabular}

преимущественно располагаются в долинах рек на высотных отметках от 20 до 240 метров над уровнем моря. Климатические изменения в ближайшем будущем могут способствовать распространению Paulownia tomentosa.

Самыми эффективными предикторами пространственного распределения павловнии из группы географических растров являются высота над уровнем моря, топографический индекс влажности и речная сеть; из набора биоклиматических растров Bioclim: годовая сумма осадков, максимальная температура самого теплого месяца года, средняя температура самой сухой четверти года и сумма осадков во влажной четверти года; из спутниковых данных - снимок, сделанный в мае (полученный в результате Tasseled-Cap-трансформации, канал В - «яркость»).

\section{СПИСОК ЛИТЕРАТУРЫ}

1. Акатов В. В. Видовое богатство древесного и кустарникового ярусов прирусловых лесов Западного Кавказа с доминированием иноземных видов // Экология, 2012, № 4, с. 276-283.

2. Василевич В. И. Доминанты в растительном покрове // Ботанический журнал, 1991, т. 76, № 12, с. 1674 1681.

3. Виноградова Ю.К., Майоров С.Р., Хорун Л.В. Черная книга флоры Средней России (Чужеродные виды растений в экосистемах Средней России). М., ГЕОС, 2009. 494 с.

4. Владимиров Д.Р., Ту Вэйго Некоторые теоретические вопросы адвентивной флоры и ее инвазионного субэлемента // Вестник Воронежского государственного университета. Серия: География. Геоэкология, 2016, № 3, c. 73-78.

5. Егошин А. В. Адвентивный компонент флоры Юга Российского Причерноморья. Моделирование пространственного распределения адвентивных видов, на примере Paulowna Tomentosa // Сочинскому националь- ному парку - 35 лет. Труды Сочинского национального парка. Выпуск 12, Сочи, Типография «Оптима», 2018, c. $140-153$.

6. Сенатор С.А. Зависимость видового разнообразия урбанофлор от ряда факторов // Вестник Удмуртского университета. Серия Биология. Науки о Земле, 2013, вып. 2, с. 23-29.

7. Chytry M. Habitat invasions by alien plants: a quantitative comparison among Mediterranean, subcontinental and oceanic regions of Europe. Journal of Applied Ecology, 2008, no. 45, pp. 448-458.

8. Davidson A.M. Do invasive species show higher phenotypic plasticity than native species and, if so, is it adaptive? A meta-analysis. Ecology Letters, 2011, no. 14, pp. 419-431.

9. Elton C.S. The ecology of invasions by animals and plants. Methuen. London, 1958. $181 \mathrm{p}$.

10. Gassmann A. Europe as a source of biological control agents of exotic invasive weeds: status and implications. Bull. Soc. Entomol. Suisse vol., 2009, no. 34, p. 313-322.

11. Goodman D. Theory of diversity-stability relationships in ecology. Quarterly Review of Biology, 1975 , no. 50, pp. 237-266.

12. Hayasaka D., Akasaka M., Miyauch D. Qualitative variation in roadside weed vegetation along an urban-rural road gradient. Flora, 2012, pp. 126-132.

13. Hulme Ph. E., Hester R. E. Biological invasions in Europe: drivers, pressures, states, impacts and responses. Biodiversity under threat. Cambridge: Royal Soc. Chem, 2007, pp. 56-78.

14. Pimm S.L. Structure of food webs. Theoretical Population Biology, 1979, no. 16, pp. 144-158.

15. Rejmanek M. Plant invasions and invisibility of plant communities. Vegetation ecology, Oxford: Blackwell, 2005, pp. 332-355.

16. Rejmanek M. A. Theory of seed plant invasiveness: the first sketch. Biological Conservation, 1996, no. 78, pp. 171-181.

17. Simberloff D. Invasion biology. Critique of a pseudoscience. Ecological Economics, 2004, no. 48, pp. 360-362. 


\section{REFERENCES}

1. Akatov V.V. Vidovoe bogatstvo drevesnogo I kustarnikovogo yarusov priruslovykh lesov Zapadnogo Kavkaza s dominirovaniem inozemnykh vidov [Species richness of woody and shrub tiers of channel forests of the Western Caucasus with a dominance of alien species]. Ekologiya, 2012, no. 4, pp. 276-283. (In Russ.)

2. Vinogradova Yu. K., Mayorov S.R., Khorun L.V. Chernaya kniga flory Sredney Rossii (Chuzherodnye vidy rasteniy $v$ ekosistemakh Sredney Rossii) [Black Book of Flora of Central Russia (Alien Plant Species in Ecosystems of Central Russia)]. Moscow, GEOS, 2009, 494 p. (In Russ.)

3. Vasilevich V.I. Dominanty v rastitel'nompokrove [Dominants in the vegetation]. Bot. Zhurn, 1991, v. 76, no. 12, pp. 1674-1681. (In Russ.)

4. Vladimirov D. R., Tu Veygo Nekotorye teoreticheskie voprosy adventivnoy flory i ee invazionnogo subelementa [Some theoretical questions of adventive flora and its invasive subelement]. Vestnik Voronegskogo gosudarstvennogo universiteta. Seriya Geografiya, Geoekologiya, 2016, no. 3, pp. 73-78. (In Russ.)

5. Egoshin A. V. Adventivnyy component flory Yuga Rossiyskogo Prichernomor'ya. Modelirovanie prostranstvennogo raspredeleniya adventivnykh vidov, na primere Paulowna Tomentosa [Adventive component of the flora of the South of the Russian Black Sea region. Modeling the spatial distribution of adventive species]. Sochinskomu natsional'nomu parku - 35 let. Trudy Sochinskogo natsional'nogo parka, Vyp. 12, Sochi: Tipografiya "Optima”, 2018, S. 140-153. (In Russ.)

6. Senator S. A. Zavisimost' vidovogo raznoobraziya urbanoflor ot ryada faktorov [The dependence of the species diversity of urban floras on some factors]. Vestnik $U d$ murtskogo universiteta. Seriya Biologiya. Nauki o Zemle, 2013, v. 2, pp. 23-29. (In Russ.)

\section{КОНФЛИКТ ИНТЕРЕСОВ}

Автор декларирует отсутствие явных и потенциальных конфликтов интересов, связанных с публикацией настоящей статьи.

Егошин Алексей Валентинович кандидат сельскохозяйственных наук, Сочинский национальный парк, г. Сочи, Российская Федерация, ORCID: orcid.org/0000-0002-7862-234X, e-mail: ecoid@ya.ru
7. Chytry M. Habitat invasions by alien plants: a quantitative comparison among Mediterranean, subcontinental and oceanic regions of Europe. Journal of Applied Ecology, 2008, no. 45, pp. 448-458.

8. Davidson A.M. Do invasive species show higher phenotypic plasticity than native species and, if so, is it adaptive? A meta-analysis. Ecology Letters, 2011, no. 14, pp. 419-431.

9. Elton C. S. The ecology of invasions by animals and plants. Methuen. London, 1958. 181 p.

10. Gassmann A. Europe as a source of biological control agents of exotic invasive weeds: status and implications. Bull. Soc. Entomol. Suisse vol., 2009, no. 3-4, p. 313322.

11. Goodman D. Theory of diversity-stability relationships in ecology. Quarterly Review of Biology, 1975, no. 50, pp. 237-266.

12. Hayasaka D., Akasaka M., Miyauch D. Qualitative variation in roadside weed vegetation along an urban-rural road gradient. Flora, 2012, pp. 126-132.

13. Hulme Ph. E., Hester R.E. Biological invasions in Europe: drivers, pressures, states, impacts and responses. Biodiversity under threat. Cambridge: Royal Soc. Chem, 2007, pp. 56-78.

14. Pimm S.L. Structure of food webs. Theoretical Population Biology, 1979, no. 16, pp. 144-158.

15. Rejmanek M. Plant invasions and invisibility of plant communities. Vegetation ecology, Oxford: Blackwell, 2005, pp. 332-355.

16. Rejmanek M. A. Theory of seed plant invasiveness: the first sketch. Biological Conservation, 1996, no. 78, pp. 171-181.

17. Simberloff D. Invasion biology. Critique of a pseudoscience. Ecological Economics, 2004, no. 48, pp. 360-362.

\section{CONFLICT OF INTEREST}

The author declares no information of obvious and potential conflicts of interest related to the publication of this article.

Alexey V. Egoshin

Cand. Sci. (Agric), Sochi National Park, Sochi, ORCID: orcid.org/0000-0002-7862-234X, e-mail: ecoid@ yandex.ru 